\title{
Effects of $\beta$-mercaptoethanol on in vitro maturation and glutathione level of buffalo oocytes
}

\author{
Pankaj A. Patel, Sandhya S. Chaudhary, Gopal Puri, Virendra Kumar Singh and Arjun B. Odedara \\ Department of Veterinary Physiology \& Biochemistry, College of Veterinary Sciences \& Animal Husbandry, Navsari \\ Agricultural University, Navsari-396450, Gujarat, India. \\ Corresponding author: Sandhya S. Chaudhary, e-mail: sandhyachaudhary6@gmail.com, \\ PAP: gamitpankaj09@gmail.com, GP: drgopalpuri@gmail.com, VKS: drvksingh1981@gmail.com, \\ ABO: arjunodedra81@gmail.com \\ Received: 20-11-2014, Revised: 25-12-2014, Accepted: 05-01-2015, Published online: 23-02-2015
}

doi: 10.14202/vetworld.2015.213-216. How to cite this article: Patel PA, Chaudhary SS, Puri G, Singh VK, Odedara AB (2015) Effects of $\beta$-mercaptoethanol on in vitro maturation and glutathione level of buffalo oocytes, Veterinary World $8(2): 213-216$.

\begin{abstract}
Aim: The present study was carried out to evaluate the effect of supplementation of $\beta$-mercaptoethanol ( $\beta$-ME) on in vitro maturation rate and glutathione (GSH) level of buffalo oocytes.

Materials and Methods: Oocytes were recovered from buffalo's ovaries collected from government approved slaughter house (near Kamela darwaza, Surat) of Surat Municipal Corporation. The obtained oocytes were in vitro matured in maturation media supplemented with $0 \mu \mathrm{M}$ (117 oocytes), $100 \mu \mathrm{M}$ (46 oocytes) and $200 \mu \mathrm{M}$ (42 oocytes) concentration of $\beta$-ME. After $24 \mathrm{~h}$ of incubation, maturation rate of oocytes and intra-cellular GSH level were determined.
\end{abstract}

Results: The results showed that the presence of $\beta$-ME did not influence $(p>0.05)$ the oocyte maturation rate. However, GSH level increased significantly $(\mathrm{p}<0.05)$ in matured oocytes when supplemented with $100 \mu \mathrm{M}$ and $200 \mu \mathrm{M} \beta-\mathrm{ME}(6.19 \pm 0.10$ and $6.37 \pm 0.20 \mathrm{pmol} /$ oocyte) as compared to control media ( $4.68 \pm 0.26 \mathrm{pmol} /$ oocyte).

Conclusion: It was concluded that $\beta$-ME may have a potential to increase the meiotic maturation of in vitro cultured oocytes and protect it from oxidative damage.

Keywords: buffalo oocytes, in vitro maturation, $\beta$-mercaptoethanol, glutathione.

\section{Introduction}

Buffalo (Bubalus bubalis) plays a prominent role in rural livestock production. Problems like late onset of reproductive maturity, seasonality of breeding, late estrus and long calving interval have been attributed to poor reproductive performance of this species [1]. To cope up with these problems, use of modern biotechnologies, such as in vitro fertilization (IVF) and embryo production are required instead of conventional breeding programs [2].

A major factor affecting in vitro mammalian embryo development is increased oxidative stress [3], which is due to high lipid content of buffalo oocytes [4]. Higher amount of reactive oxygen species (ROS) can alter cellular molecules; induce developmental block, apoptosis and fragmentation of embryos [5]. It has been demonstrated that addition of low molecular thiol compound such as $\beta$-mercaptoethanol ( $\beta$-ME) and cysteamine to the maturation medium causes an increase in intracellular glutathione $(\mathrm{GSH})$ synthesis $[6,7]$ and leads to low oxidative stress in many species [8].

$\beta$-ME and GSH both improve the cell survival by decreasing apoptotic cell death under "redox" state [9]. GSH directly influences cell death, while $\beta$-ME has an indirect effect by supporting increase in

Copyright: The authors. This article is an open access article licensed under the terms of the Creative Commons Attributin License (http:// creative commons.org/licenses/by/2.0) which permits unrestricted use, distribution and reproduction in any medium, provided the work is properly cited. intracellular GSH level [5]. Buffalo oocytes can synthesize de novo during in vitro maturation (IVM) [7] and $\beta$-ME increases cumulus cells expansion which help in GSH synthesis [10]. So far as buffalo oocytes are concerned, meagre studies have been carried to know the effects of $\beta$-ME on cumulus expansion of oocyte and intracellular GSH content.

Therefore, the present study was carried out to evaluate the effect of supplementation of $\beta$-ME on IVM rate and GSH level of buffalo oocytes.

\section{Materials and Methods}

\section{Reagents and media}

All the chemical and media used in the present study were purchased from Sigma (USA).

\section{Collection of ovaries}

Ovaries were collected from sexually matured buffaloes immediately after slaughter from nearby government approved slaughter house (near Kamela darwaza, Surat) of Surat municipal corporation and transported to the laboratory in sterile normal saline (NSS:0.85\%) solution fortified with antibiotic (50 $\mu 1 / \mathrm{L}$ Gentamicin) at $38-39^{\circ} \mathrm{C}$ temperature. At laboratory, ovaries were washed in $70 \%$ ethanol for $1 \mathrm{~min}$. to reduce contamination followed by washing in $0.85 \%$ $\mathrm{NaCl}$ twice for $1 \mathrm{~min}$.

\section{Oocyte recovery}

After final washing, cumulus oocyte complexes (COCs) were aspirated from non-atretic surface 
follicles $(2-8 \mathrm{~mm})$ using 18 -guage needle connected to a $5 \mathrm{ml}$ sterile syringe containing oocyte collection media. Further aspirated oocytes were searched and graded as per Khandoker et al. [11]. A, B and C grade oocytes were used for IVM.

\section{Maturation of oocytes}

After final washing with oocyte collection media, oocytes of A, B and C grade were equally distributed in three groups viz: control Group I (117 oocytes) and treatment Groups-II (46 oocytes) and III (42 oocytes). In control group, only basic maturation media (TCM-199 supplemented with $0.2 \mathrm{mM}$ sodium pyruvate, $10 \%$ fetal bovine serum, $3 \mathrm{mg} / \mathrm{ml}$ bovine serum albumin and $10 \mathrm{IU} / \mathrm{ml} \mathrm{hCG}$ ) was used while in treatment Group-II and III control media supplemented with $100 \mu \mathrm{M}$ and $200 \mu \mathrm{M} \beta$-ME respectively was used. Before transferring to maturation media, oocytes were washed once with respective maturation media. Each group was individually placed in $50 \mu \mathrm{l}$ droplet of maturation medium containing 5-10 oocytes covered with mineral oil in a sterile petridish and kept at $38.5^{\circ} \mathrm{C}, 5 \% \mathrm{CO}_{2}$ and $95 \%$ humidified air in $\mathrm{CO}_{2}$ for $24 \mathrm{~h}$.

\section{GSH content and maturation rate of oocytes}

Maturation of oocyte assessed on the basis of their cumulus layer expansion as per Khandoker et al. [11]. GSH level estimation of oocytes was carried out in all groups after $24 \mathrm{~h}$ of maturation. Oocytes were carefully denuded by repeated pipetting, washed several times in $1 \mathrm{x}$ phosphate buffered saline and 10-12 oocytes from each group were stored at $-20^{\circ} \mathrm{C}$ in eppendorf for further use. On the day of assay, the samples were thawed and $500 \mu \mathrm{l}$ of ice-cold 5\% metaphosphoric acid added to each sample. Vortexing performed for 3-5 min. After that sonication was performed for $5 \mathrm{~min}$. Samples were then centrifuged (10 min; $3000 \times \mathrm{g}$ ) in cryo-centrifuge machine at $4^{\circ} \mathrm{C}$ and 100 $\mu l$ of supernatant was recovered. Further estimation of GSH was done with the help of GSH Assay Kit (Calbiochem ${ }^{\circledR}$ USA).

\section{Statistical analysis}

Data pertaining to oocyte maturation were analyzed by SPSS software performing Chi-square test and for data pertaining to GSH level by one-way ANOVA among control and treatment groups. A significance level of $p<0.05$ was used throughout this study.

\section{Results}

The effects of supplementation of $\beta$-ME on IVM rate and GSH level of buffalo oocytes is presented in Table- 1 . The results showed that the presence of $\beta$-ME did not influence the oocyte maturation rate although higher maturation rate was observed in $\beta$-ME-100 and $200 \mu \mathrm{M}$ groups as compared to control. However, intra-cellular GSH level increased significantly $(p<0.05)$ in the presence of 100 and $200 \mu \mathrm{M} \beta-\mathrm{ME}$
Table-1: Effects of $\beta-M E$ on of oocytes and its GSH level in buffalo.

\begin{tabular}{lccc}
\hline Groups & $\begin{array}{c}\text { Total } \\
\text { no of } \\
\text { oocytes }\end{array}$ & $\begin{array}{c}\text { No. of } \\
\text { matured } \\
\text { oocytes (\%) }\end{array}$ & $\begin{array}{c}\text { GSH Level in } \\
\text { matured oocytes } \\
\text { (pmol/oocyte) }\end{array}$ \\
\hline Control & 117 & $78(66.7)$ & $4.68 \pm 0.26^{\mathrm{a}}$ \\
$\beta-\mathrm{ME}-100 \mu \mathrm{M}$ & 46 & $35(76.1)$ & $6.19 \pm 0.10^{\mathrm{b}}$ \\
$\beta-\mathrm{ME}-200 \mu \mathrm{M}$ & 42 & $32(76.2)$ & $6.37 \pm 0.20^{\mathrm{b}}$ \\
\hline
\end{tabular}

$\beta-M E=\beta$-mercaptoethanol, IVM $=$ In vitro maturation, $\mathrm{GSH}=$ Glutathione

(6.19 \pm 0.10 and $6.37 \pm 0.20 \mathrm{pmol} /$ oocyte) as compared to control $(4.68 \pm 0.26 \mathrm{pmol} /$ oocyte $)$.

\section{Discussion}

Antioxidants function as autocrine and paracrine factors that influence growth, differentiation and retardation of developing follicles. Presence of GSH, $\beta$-ME is beneficial for follicle development, and there may be an interaction between exogenous antioxidant and developing follicles. Exogenous antioxidants influence follicle growth and nuclear maturation of intra-follicular oocytes. $\beta$-ME is a thiol compound, acting as an antioxidant and promotes embryo development $[12,13]$.

The results of the present study revealed that the addition of $\beta$-ME $(100 \mu \mathrm{M}$ and $200 \mu \mathrm{M})$ to the maturation medium did not increase maturation rate, as also reported in porcine oocytes [14]. However, higher numbers of M-II oocytes were found when denuded oocytes were cultured in maturation medium supplemented with $25 \mu \mathrm{M} \beta$-ME [15]. Similarly, supplementation of $\beta$-ME positively influence percentage of oocytes from pre-pubertal Boer goats progressing to metaphase II stage during IVM [16]. It has also been reported that supplementation of $\beta$-ME in maturation media have positive effect on expansion of COCs and maturation rate of oocytes of bovine as well as pig [10,17], apart for impact on fertilization rate [18] and improves embryo development rate $[19,20]$.

The effect of $\beta$-ME may have been mediated through the synthesis of GSH which is known to play an important role in protecting the cell or embryos from oxidative damage. Exogenous $\beta$-ME is able to increase GSH synthesis by reducing cystine to cysteine [21] and increased GSH level promotes embryonic development by maintaining intracellular redox state [22]. In the present study also, significantly higher GSH level was observed in groups having maturation medium supplemented with $100 \mu \mathrm{M}$ and $200 \mu \mathrm{M} \beta$-ME than control groups. Similar results were found in bovine oocytes and embryos $[7,15,22]$, as well as pig oocytes [12]. GSH itself plays a critical role in protecting the cell from oxidative damages [23-26]. These results warrant the supplementation of exogenous $\beta$-ME in basic oocyte maturation medium for improvement of IVF. 


\section{Conclusion}

From the present study, it can be concluded that addition of $\beta$-ME at different concentration in maturation media helps in the synthesis of GSH that protects the degeneration of oocytes from ROS during IVM and might enhance the process of maturation of oocyte.

\section{Authors' Contributions}

SSC along with GP designed the experiment and PAP conducted the experiment with the help of ABO. GP and VKS helped in analyzing the data and preparing the manuscript. SSC, GP, VKS and PAP reviewed the manuscript. All authors read and approved the final manuscript.

\section{Acknowledgments}

The authors are thankful to Dean, Vanbandhu College of Veterinary Sciences \& A.H., NAU, Navsari for providing financial assistance and research facilities to conduct this experiment.

\section{Competing Interests}

The authors declare that there is no conflict of interests regarding the publication of this paper.

\section{References}

1. Nandi, S., Ravindranatha, B.M., Gupta, P.S.P. and Sarma, P.V. (2002) Timing in sequential changes in cumulus cells and first polar body extrusion during in vitro maturation of buffalo oocytes. Theriogenology, 57(3): 1151-1159.

2. Kumar, D. and Anand, T. (2012) In vitro embryo production in buffalo: Basic concepts. J. Buffalo Sci., 1(1): 50-54.

3. Tsunoda, S., Kimura, N. and Fujii, J. (2014) Oxidative stress and redox regulation of gametogenesis, fertilization, and embryonic development. Reprod. Med. Biol., 13(2): 71-79.

4. Boni, R., Sangella, L., Dale, B., Rovello, S., Di Palo, R. and Barbieri, V. (1992) Maturazione in vitro dioocitibufalini: Indagineultrastrutturale. Acta Med. Vet., 38: 153-161.

5. Guerin, P., El Mouatassim, S. and Menezo, Y. (2001) Oxidative stress and protection against reactive oxygen species in the pre-implantation embryo and its surroundings. Hum. Reprod. Update. 7(2): 175-189.

6. DeMatos, D.G. and Furnus, C.C. (2000) The importance of having high glutathione (GSH) level after bovine in vitro maturation on embryo development: Effect of $\beta$ - mercaptoethanol, cystein and cystin. Theriogenology, 53(3): 761-771.

7. DeMatos, D.G., Furnus, C.C., Moses, D.F., Martinez, A.G. and Matkovic, M. (1996) Stimulation of glutathione synthesis of in vitro matured bovine oocytes and its effect on embryo development and freezability. Mol. Reprod. Dev., 45(4): 451-457.

8. Dea, A.K., Malakar, D., Aksheya, Y.S., Jenaa, M.K., Garga, S., Duttaa, R. and Sahua, S. (2011) In vitro development of goat (Capra hircus) embryos following cysteamine supplementation of the in vitro maturation and in vitro culture media. Small Rumin. Res., 96: 185-190.

9. Gong, S.P. and Lim, J.M. (2009) Effects of $\beta$-Mercaptoethanol on the Growth of Preantral Follicles and the maturation of intrafollicular oocytes. Asian Aust. J. Anim. Sci., 22(1): $35-41$.

10. Nasiri, Y. and Beheshti, R. (2012) Effect of $\beta$-mercaptoethanol on in vitro maturation on oocyte of Murrah buffalo. Res.
Opin. Anim. Vet. Sci., 2(5): 377-380.

11. Khandoker, M., Imai, K., Takahashi, T. and Hashizume, K. (2001) The role of gelatinase on follicular atresia in the bovine ovary. J. Biol. Reprod., 65(3): 726-732.

12. Abeydeera, L.R., Wang, W.H., Cantley, T.C., Prather, R.S. and Day, B.N. (1998) Presence of $\beta$-mercaptoethanol can increase the glutathione content of pig oocytes matured in vitro and the rate of blastocyst development after in vitro fertilization. Theriogenoloy, 50(5): 747-756.

13. Tao, Y., Zhou, B., Xia, G., Wang, F., Wu, Z. and Fu, M. (2004) Exposure to L- ascorbic acid or $\alpha$-tocopherol facilitates the development of porcine denude oocytes from metaphase I to metaphase II and prevents cumulus cells from fragmentation. Reprod. Domest. Anim., 39(1): 52-57.

14. Oh, S.A., Chung, Y.C., Kim, C.K., Shin, H.A., Choi, S.S., Yeon, S.E., Park, J.S., Hwang, S.S. and Yoon, Y.H. (2000) Effect of $\beta$-Mercaptoethanol during in vitro maturation on in vitro fertilization and glutathione concentration in porcine oocytes. Asian Aust. J. Anim. Sci., 13: 221.

15. Ullah, I., Jalali, S., Shami, S.A. and Farooq, K. (2006) Effect of 2-mercaptoethanol on Nili Ravi buffalo oocytes during in vitro maturation. J. Anim. Vet. Adv., 5: 380-385.

16. Lv, L., Yue, W., Liu, W., Ren, Y., Li, F., Lee, K.B. and Smith, G.W. (2010) Effect of oocyte selection, estradiol and antioxidant treatment on in vitro maturation of oocytes collected from prepubertal Boer goats. Ital. J. Anim. Sci., 9: e11.

17. Park, S.H. and Yu, I.J. (2012) The effect of MEM vitamins and $\beta$-mercaptoethanol on porcine embryonic development, reactive oxygen species and apoptosis. J. Anim. Vet. Adv., 11(14): 2576-2583.

18. Bai, J., Hou, J., Guan, H., Yan, F., Cui, X., Liu, L., Wang, S. and An, X. (2008) Effect of 2-mercaptoethanol and cysteine supplementation during in vitro maturation on the developmental competence of oocytes from hormone-stimulated lambs. Theriogenol. 70(5): 758-764.

19. Shang, J.H., Huang, Y.J., Zhang, X.F., Huang, F.X. and Qin, J. (2007) Effect of ß-mercaptoethanol and buffalo follicular fluid on fertilization and subsequent embryonic development of water buffalo (Bubalusbubalis) oocytes derived from in vitro maturation. Ital. J. Anim. Sci., 6: 751-754.

20. Mishra, A., Chandra, V. and Sharma, G.T. (2010) Effect of epidermal growth factor on in-vitro maturation of buffalo oocytes and subsequent development with insulin-like growth factor-1 and B-mercaptoethanol. Indian J. Anim. Sci., 80(8): 721-724.

21. Issels, R.D., Nagele, A., Eckert, K.G. and Wilmanns, W. (1988) Promotion of cystine uptake and its utilization for glutathione biosynthesis induced by cysteamine and N-acetylcysteine. Biochem. Pharmacol., 37(5): 881-888.

22. Takahashi, M., Nagai, T., Hamano, S., Kuwayama, M., Okamura, N. and Okano, A. (1993) Effect of thiol compounds on in vitro development and intracellular glutathione content of bovine embryos. Biol. Reprod., 49(2): 228-232.

23. Kim, M.K, Fibrianto, Y.H., Oh, H.J, Jang, G., Kim, H.J., Lee, K.S., Kang, S.K., Lee, B.C. and Hwang, W.S. (2004) Effect of B-mercaptoethanol or epidermal growth factor supplementation on in vitro maturation of canine oocytes collected from dogs with different stages of the estrus cycle. J. Vet. Sci., 5(3): 253-258.

24. Li, X.X., Lee, K.B., Lee, J.H., Kim, K.J., Kim, E.Y., Han, K.W., Park, K.S., Yu, J. and Kim, M.K. (2014) Glutathione and cysteine enhance porcine preimplantation embryo development in vitro after intracytoplasmic sperm injection. Theriogenology., 81(2): 309-314.

25. Choe, C., Yong-Won, S., Eun-Jin, K., Cho, S.R., Hyun-Jong, K., Sun-Ho, C., Man-Hye, H., Jaehee, H., Dong-Soo, S. and Dawon, K. (2010) Synergistic effects of glutathione and Beta-mercaptoethanol treatment during in vitro maturation 
of porcine oocytes on early embryonic development in a culture system supplemented with L-cysteine. J. Reprod. Dev., 56(6): 575-582.

26. Akaki, Y., Yoshioka, K., Noguchi, M., Hoshi, H. and Funahashi, H. (2009) Successful piglet production in a chemically defined system for in vitro production of porcine embryos: Dibutyryl cyclic AMP and epidermal growth factor-family peptides support in-vitro maturation of oocytes in the absence of gonadotropins. J. Reprod. Dev., 55(4): 446-53.

$* * * * * * * *$ 